\title{
Sufficiency Economy Philosophy for Sustainable Zero Plastic Waste
}

\author{
Kannikar Khaw-ngern ${ }^{1}$, Prateep Peuchthonglang ${ }^{2}$, Lampong Klomkul ${ }^{3}$, Chainarong Khaw-ngern ${ }^{4}$ \\ ${ }^{1}$ Faculty of Buddhism, Mahachulalongkornrajavidyalaya University, \\ ${ }^{2}$ Faculty of Business Administration and Liberal Arts, Rajamangala University of Technology Lanna, \\ ${ }^{3}$ Faculty of Education, Mahachulalongkornrajavidyalaya University, \\ ${ }^{4}$ Faculty of Humanities, Mahachulalongkornrajavidyalaya University \\ ${ }^{1}$ kannikar.khaw@gmail.com, ${ }^{2}$ Khun_Jedrin@hotmail.com, ${ }^{3}$ research.mcu@gmail.com, ${ }^{4}$ chainarong.kha@mcu.ac.th
}

\begin{abstract}
Plastic wastes has become a global problem, and Thailand produces about two million tonnes of plastic waste per year, around $12 \%$ of total waste. The purpose of this article is to examine the causes of plastic waste in Thailand, to study the goals of Thailand's Roadmap on Plastic Waste Management 2018-2030 and Master Plan on Solid Waste Management 2016-2021, to examine the SDGs Goal 12 regarding waste reduction and sustainable consumption and production, and to investigate the principles of Sufficiency Economy Philosophy (SEP). Documentary study and literature review were used for data collection. Plastics waste and pollutions and inappropriate waste management have caused a lot of problems to people and communities and they cause contamination and residual cumulative impacts on the environment. The result showed that single-use plastics was a major factor of increasing plastic waste, especially during and after COVID-19, and inappropriate waste management has accounted for negative impacts on public well-being, communities, and environment. Sufficiency Economy Philosophy, when being applied to waste management, could play an important role in changing consumer's behavior towards waste reduction because it influenced individuals to be aware of the impacts that their actions and consumptions may have on the environment, and subsequently their livelihoods. Thus, SEP will promote the ban of single-use plastic under the Roadmap, strengthen the waste management of 3R (Reduce, Reuse, Recycle) under the Master Plan, and contribute to sustainable consumption and production under SDG Goal 12.
\end{abstract}

Keywords

Plastic Waste Management, Zero Waste, Sufficiency Economy Philosophy, SDG Goal 12

Article Received: 10 August 2020, Revised: 25 October 2020, Accepted: 18 November 2020

\section{Introduction}

At the beginning of 2020, Thailand has banned single-use plastic bags with the hope to reduce plastic waste that damages the environment and oceanic ecosystem. However, the banning scheme is hindered by the spread of coronavirus pandemic. Due to the lockdown policy and work-at-home measure, people have to stay home and require more delivery service for food and goods. Plastic waste in Bangkok metropolitan has increased by $62 \%$ in April. Even when the pandemic eases, many companies and organizations still have their employees work at home and people have got used to online shopping and food delivery services. Environmentalists are afraid that Thailand can simply be a pointer for the single-use plastic waste situation elsewhere in Southeast Asia, home to four of the world's top five plastic polluters of the ocean. With the amount of plastic waste which is contaminated items from takeaway bags to containers, bottles and cups, made up more than $80 \%$, Thailand is likely to see a surge of $30 \%$ nationwide this year, which comes from consumer behaviour shifting towards food deliver [1].

In 2017, Thailand's vision has been set Twenty-Year National Strategy 2017-2036 under "Stability, Prosperity and Sustainability", stressing or promoting a pollution-free economic growth with environmentally-friendly production and consumption, popular and multisectoral cooperation, Sufficiency Economy Philosophy, and internal strengthening with international linkages. To pursue this vision and achieving these goals in the future, the Thailand 4.0 policy has been established for investments in infrastructure and industrial development as well as environmental health program preparedness, based on awareness raising and capacity building in the monitoring of the impacts of environmental changes and pollution, and the prevention for aiming towards a happy co-habitation and balanced economic, social and environmental development. The National Master Plan on Waste Management 20162021 was approved with an objective to create an integrated waste management plan. Some of the key concepts under the Master Plan are the reduction of wastes at the source, the centralization of the waste disposal system and engagement and shared responsibilities of all sectors. As an example, government with cooperation of shopping malls and convenience stores promotes the ban of single-use plastic bags and encourages consumers to use reusable cloth shopping bags instead to reduce the amount of wastes. Additionally, as the government's Roadmap on Plastic Waste Management for 2018-2030, Thailand hopes to be free of plastic single-use plastics, i.e. plastic bags, styrofoam food boxes, plastic straws, and single-use plastic cups by the end of 2022. The goal is to reduce Thailand's plastic ocean waste at least $50 \%$ by 2027 .

\section{Thailand's Roadmap Towards Sustainable Plastic Waste Management}

Plastic provides variety of benefits for our daily life including packaging for food and goods, healthcare products, electronic gadgets and devices, even automobile spare parts due to its light weight, flexible and easy to form different shapes, shatter resistance, and less cost. However, 
plastic waste causes a lot of problems to the environment and threatens the ecosystem. It flows into waterways and ultimately the oceans harming marine lives. It also pollutes the land and the air negatively affecting wildlife, wildlife habitats, and humans [2]. Countries around the world have been developing different plastic waste management policies to tackle the problem, especially single-use plastics. For example, 27 countries enforced tax collection from the producers of single-use plastic bags while 30 charged consumers for single-use bags, according to UNEP.

For Thailand, the Roadmap on Plastic Waste Management 2018-2030 was acknowledged by the cabinet on April 17, 2019 as to be a policy framework for tackling the plastic waste problems. The objective of the roadmap is to stop the use of plastics and replace it with environmentally friendly materials [3]. At the beginning of 2020, the government launched its own ban on single-use bags at most shopping malls and convenience stores and expect a complete ban in 2021 in order to lessen plastic and debris in the sea [4]. This has been enforced, along with community outreach, social media campaigns and educational programs to raise awareness of plastic waste and plastic pollutions. When being aware of the problems, young people, professionals and academics can contribute their ideas to best practices for sustainable plastic waste management. Their intergenerational knowledge and actions could be a catalyst for changes.

Thailand generates about two million tons of plastic waste each year, $25 \%$ of which is recycled, according to the Pollution Control Department (PCD). The goal of Thailand's waste management bill is to make plastic $100 \%$ recyclable by 2027 . If the bill becomes law, it will help to end single-use plastic bags, a key factor in its implementation of $3 \mathrm{R}$ which is a concept to Reduce, Reuse and Recycle. Manufacturers would also be mandated to put their plastic waste to good use under the Extended Producer Responsibility procedure (EPR). Additionally, the law relating to plastic waste management will be able to enhance the country's circular economy in the future. According to the Public Private Partnership for Plastic and Waste Management (PPP), plastic microbeads, cap seal, and OXO was fully phased out in 2019. And the next target is to fully phase out <36-micron shopping bags, Styrofoam food packaging, single-use plastic cup and straws by 2022. Its ambitious goal is to reduce plastic marine debris by $50 \%$ and recycle $100 \%$ of plastic waste by the year 2027 [5]. (Figure 1)



Figure 1. Thailand's 20 years roadmap [6]
Over the first few months of 2020 after the ban of single-use plastic, Thais became more aware of the impact of singleuse plastics on the environment and joined hands to reduce their consumption. But once the spread of Covid-19 struck the country, the amount of plastic waste generated has sprung up by $15 \%$, and in April Bangkok's plastic volume went up to $62 \%$ due to the lockdown policy and work-athome scheme. Of all the plastic waste items, $80 \%$ comprised bubble wrap, takeaway bags and containers, bottles, and cups [7]. However, The Natural Resources and Environment Ministry with cooperation of Thailand Responsible Business Network (TRBN) launched the "Sending plastic bags home" to tackle the rise of household plastic waste due to the stayhome measure [8].

In 2016, community-based waste generation in Thailand reached 27.06 million tonnes/year or 74,130 tonnes/day nationwide. Of this volume, $21 \%$ was recovered, $36 \%$ was properly disposed. The improper disposed waste was as much as 11.7 million tonnes/year or $43 \%$ of all generated waste. (Figure 2)

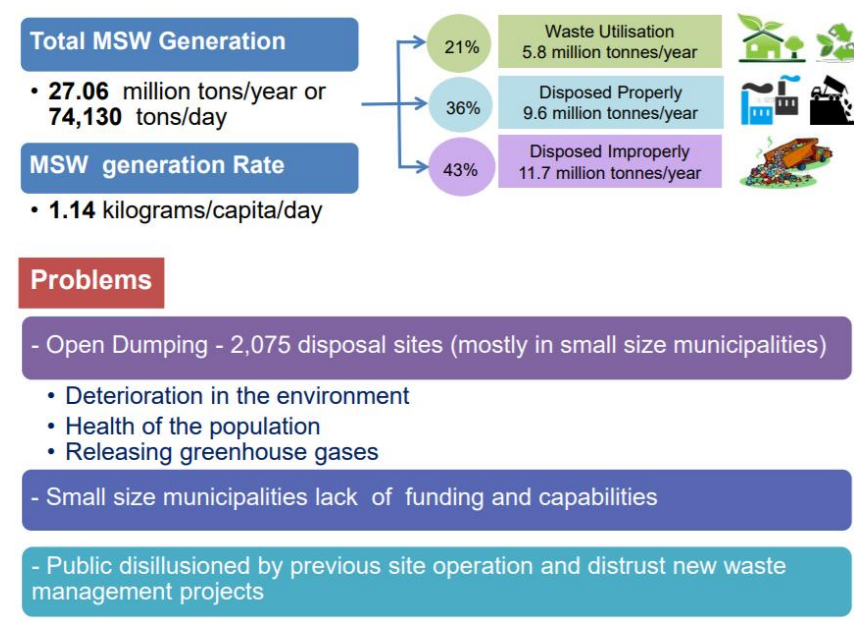

Figure 2. Situation of municipal solid waste management in Thailand 2016 [9]

With strong commitment to tackle waste problems, including plastic waste which was accounted for $17 \%$ out of the total waste, the Thai cabinet approved the National Waste Management Master Plan on May 3, 2016 with the aim to apply 3R; Reduce, Reuse, Recycle into waste management, increase efficiency of waste separation and collection, apply integrated technologies such as waste to energy, raise awareness, build capacity, and provide educational program about waste [10]. (Figure 3) Under the master plan framework, many waste disposal measures were developed for systematic waste management including waste reduction at source, manufacturer responsibility, increasing capacity of household waste management, and educational program for developing knowledge and raising awareness of municipal waste and household hazardous waste. (Figure 4) 


\section{National Waste Management Master Plan}

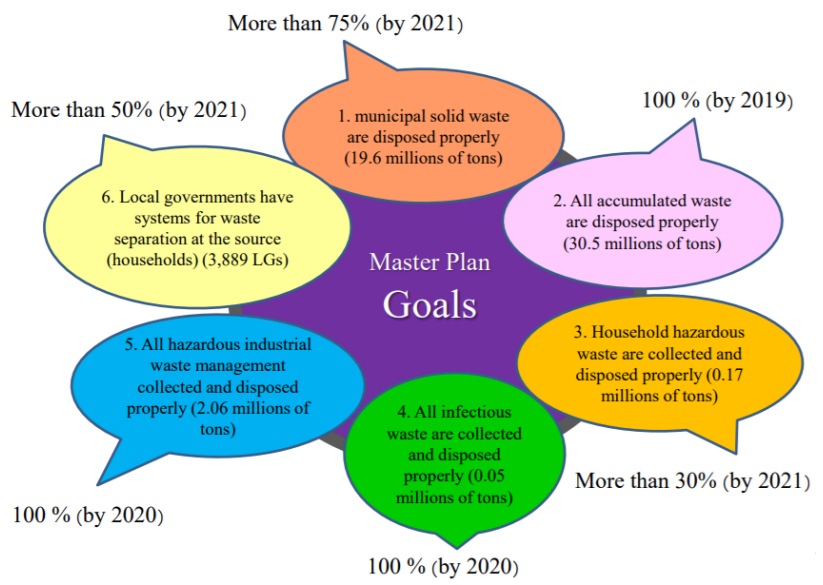

Figure 3. National Waste Management Master Plan Goals [11]

National Waste Management Master Plan

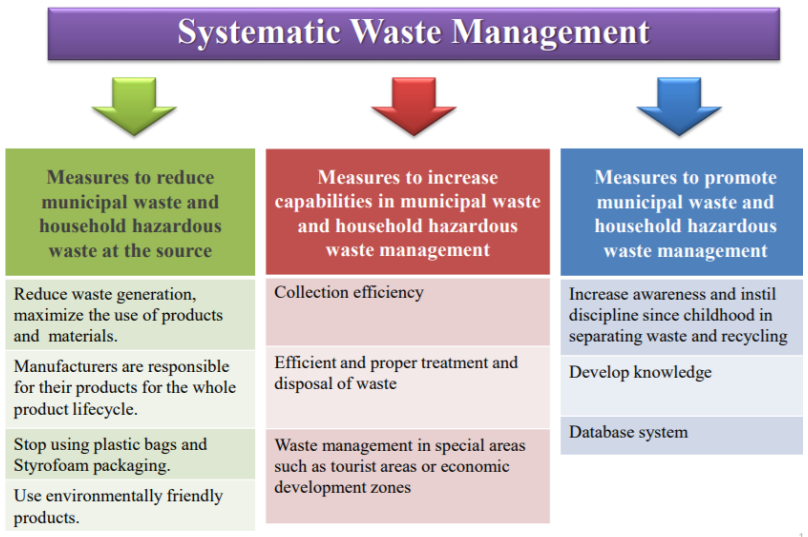

Figure 4. Systematic Waste Management [12]

\section{SDG Goal 12: Ensure Sustainable Consumption And Production Patterns}

Due to massive manufacture of plastic and the huge amount of plastic waste, consumers all over the world are pushing for change, but it is not easy for each individual or each organization to take responsibility and action on the problem. Plastic is common material that can be found in almost all products sold in supermarkets and shopping malls, from food packaging, healthcare and cleaning products, office supplies, to clothes, even electronic device. It is a hard and complicated job to eliminate plastic from the waste stream as it requires a much more effort of all sectors than refusing single-use straws or ban on single use of plastic bags. SDG Goal 12; Ensure sustainable consumption and production patterns, was launched with the goal to promote resource and energy efficiency through the interconnectedness of the private and public sectors. (Figure 5)
ENSURE SUSTAINABLE CONSUMPTION

AND PRODUCTION PATTERNS

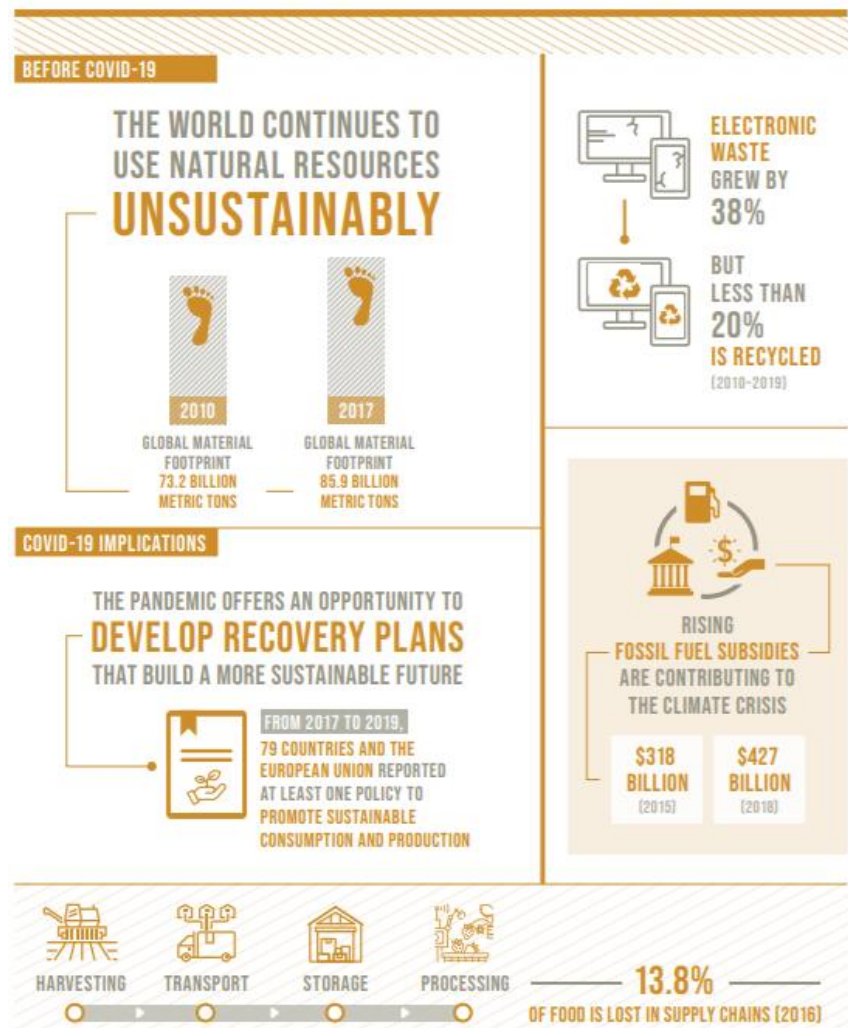

Figure 5. Sustainable Development Goals [13]

The SDG Goal 12 is closely related to the circular economy practices [14]. The Goal 12 and circular economy (CE) share the same goal to promote resource efficiency and regenerate natural system. The European Commission established the European strategy for plastics in a circular economy to transform the way plastic products are designed, used, produced and recycled in the EU, and help reach global climate commitments. EU governments have also agreed to ban single-use plastics and required manufacturers to take responsibility for their plastic products and packaging after sale. The EU revised its waste legislation to make it fit for the future and significantly steps up recycling of municipal waste (target of $55 \%$ by 2025 and $65 \%$ by 2035 ) and packaging waste (target of $65 \%$ by 2025 and $70 \%$ by 2030 and for plastics the 2030 target is 55\%) [15]. In 2021, labels informing consumers about the presence of plastics in products and about the environmental impact of littering will come into force.

Although lots more people have become aware of plastic problem, they are unlikely to change their behavior, especially in developing countries. Most producers and consumers daily use single-use plastic and dump all plastic waste with other items without sorting despite their growing sensitization of plastic waste. Moreover, plastic recycling is complicated because daily-use products are made from a variety of polymer materials. To increase recycling rates, there needs to be proper identification and separation. To tackle with plastic waste problem and move towards sustainable consumption and production of plastic, all economic players including policy-makers, producers, business sectors and consumers worldwide are required to 
contribute and take steps rethinking the way economic development is pursued.

For Thailand, the $3 \mathrm{R}$ concept has been taken into the waste management program as guideline for sustainable consumption and production. To fight the plastic waste problem, only government's plans, policies, law, and regulations are not enough to fix the problem. Success will be possible with the coordination and collaboration from all parties in the country including government, private sector, education sector, public/NGOs sector, and religious sector based on participatory Civil-State concept. (Figure 6) Obviously during the first five months of the ban of singleuse plastic bags, the country reduced the use of plastic bags by 2 billion, or about 5,765 tonnes resulted from the collaboration from giant retailers, plastic manufacturers, and leading shopping malls and convenience stores as well as the consumers themselves.

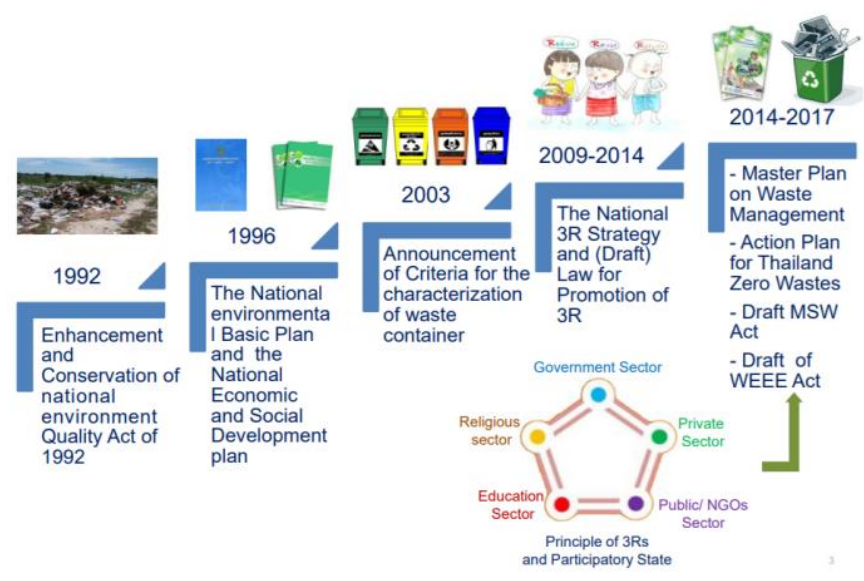

Figure 6. Principle of 3Rs and Management Timeline [16]

Thailand developed its masterplan and roadmap for sustainability consumption and production based on Sufficiency Economy Philosophy (SEP). It is a development plan on a balance between the conservation and the utilization of natural resources [17]. Three main strategies include 1) Enhance and develop the potential of human capital; 2) strengthen the economy and enhance competitiveness on a sustainable basis; and 3) promote green growth for sustainable development. Systematic policies, measures and mechanisms were established to advance sustainable consumption and production in all sectors including the government, manufacturing and services and civil society, as well as promoted the mindsets of responsible consumption and production.

\section{Sufficiency Economy Philosophy For Sustainable Zero Plastic Waste}

Due to the increasing demand of plastic products, global production of plastics in 2018 almost reached 359 million tonnes, $51 \%$ of which is distributed in Asia. Of all plastic production, packaging is accounted for $39.9 \%$ which is the highest plastic demand computed by segment [18]. It is estimated that 8 million metric tons of plastics enters our ocean every year accumulating with the estimated 150 million metric tons that currently circulate our marine environments. And if we don't take any action, the ocean could be filled with 250 million metric tons in less than 10 years [19].

Thailand is one of the biggest plastic waste polluters that ranks 6th place of world biggest contributor of ocean waste. Each year 1.03 million tons of plastic waste is generated worldwide, with $3 \%$ of which finding its way into the ocean [20]. The masterplan and roadmap for sustainability consumption and production is developed on the foundation of Sufficiency Economy Philosophy (SEP). It focuses on the $3 \mathrm{R}$ concept to manage municipal waste, including plastic waste, by promoting waste reduction, reuse, and recycle approach. The government has also launched different measures to tackle plastic problems such as the ban of three types of plastic - microbeads, cap seals and oxo-degradable plastics; promoting biodegradable plastic packaging by allow companies to claim deductions of up to 1.25 times for expenses if they buy biodegradable plastic packaging during 2019-21 [21]. Although the plan aims to reduce plastic waste and expects to use $100 \%$ recycled plastic by 2027 with the attempts from the government to achieve the plan, the $3 \mathrm{R}$ concept has not been implemented well enough. The main reasons include too much demand and production of plastic, lack of knowledge on environmental problems from plastic, unawareness to conserve the environment, and unattractive incentives for sorting and recycling waste.

Sufficiency economy philosophy is considered a new paradigm for development and aims to improve human wellbeing as well as providing a balanced way of living for people. It comprises three principles which are moderation (knowing what is enough, not extreme and overindulgence), reasonableness (understanding the connection between cause and effect), and prudence (self-immune when facing sudden changes arising from internal and external changes) on the basis of virtues (positive values of a person or positive norms of a group) and knowledge. In the case of plastic waste management, Sufficiency Economy Philosophy can guide individuals to practice $3 \mathrm{R}$ concept or even $5 \mathrm{R}$.

It is important to help practitioners realize the real value in the practice of plastic waste management through educational programs and campaigns. Individuals know the situation of plastic waste in their society and understand its harm to the environment. They are aware the impacts of their actions and consumptions that may have on the environment, and subsequently their livelihoods. This awareness can lead them to lower their demand on the plastic items or refuse to get more new items while the existing ones are still usable. For example, they reuse the plastic utensils which still works without replacing them with new ones; refuse single-use plastic bags, cups, and straws; carry cloth bags and reusable plastic containers with them. Consumption with reasonableness and with consideration in all modes of conduct could prevent the long-term impacts on society and environment. With the awareness, they are willing to sort the plastic waste for recycle and recover other broken items to make them usable again. This systemic practice can be started from an individual or a household and shared to others in the community, then one community to other communities. When communities follow these practices and implement the waste management program effectively, those lessons have too frequently been replicated elsewhere. 
With the intervention from local authorities, private agencies, volunteers or activists to provide information about the situation of plastic waste and its harm to life and environment as well as proper sorting practices for different types of plastic, an individual, household, or community can start their plastic waste management based on sufficiency economy philosophy. To encourage people, households, and communities to implement this waste management practice in long term, the government and business sector can work together on incentive programs to reward the practitioners who join the recycling activities. The rewards can vary from cash, discounts from local stores, vouchers from shopping malls, or even social recognition. (Figure 7) For low-income households, the government can also provide youth with employment opportunity as collectors and sorters. It is also important to monitor those practices and evaluate progress of the management program through following up and evaluation scheme. The government and local authorities also need to provide necessary tools such as recycling bins and collection schedule for local communities.

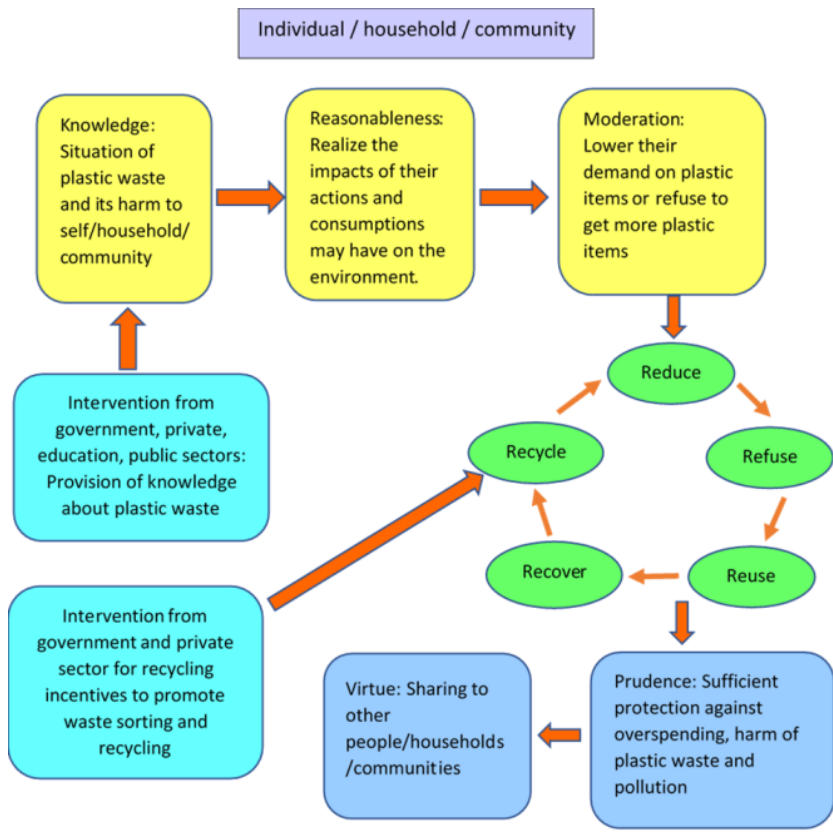

Figure 7. Plastic Waste Management based on Sufficiency Economy Philosophy

The sustainable waste management should not only simply inform people the plan and the target, but the government and local authorities should actively take action with collaboration from business sector, education sector, and public sector to provide them practical sustainable consumption patterns and should define what the consumers can do to reduce negative impacts that threaten sustainability (through purchase, use, re-use or disposal). For the change of behaviour to be sustained and not only be adopted short-term or for one time, a longer-term relationship should be built with the consumers to embed new consumption behaviour. The progress on plastic waste management resulted from the behaviour change should be monitored and informed to the people in communities. The sustainability information should be added in educational programs for consumers to better understand and act on sustainability issues.
The philosophy of the Sufficiency Economy guides individuals to live their lives and deal with problems with knowledge, reasonableness, prudence, moderation, and virtue. Thus, they not only live their lives in a balanced way, but they are able to maintain sustainability for the future. By focusing on a balanced approach, Sufficiency Economy Philosophy promotes the nation to modernize without resisting globalization but provides a means to counteract negative outcomes from rapid economic and cultural transitions [22]. When applying the philosophy in plastic waste management approach, consumers, the key factor of waste reduction, will be more aware of the problem and take more action in the waste management practice. This can be applied to the individual level, the community level and the national level. In addition, a way of life based on sufficiency economy principles can help individuals to create balance between their wellbeing and environmental sustainability, and be able to cope appropriately with significant challenges arising from extensive and rapid socioeconomic, environmental, and cultural changes in the world [23].

\section{Conclusion}

Thailand Environment Institute has revealed the fact in regard to environmental problems that plastic waste increased during the lockdown up to $15 \%$, or up from around 5,500 tons a day to 6,300 tons a day due to the spread of Covid-19. Importantly, it is found that this increased amount of plastic waste related to the shift in people's lifestyle following the pandemic. In a postCOVID-19 world, people's behaviours and attitudes will change. From the basic practices like hand hygiene, to the digital platforms like distance learning and virtual meetings, we have seen that it is possible to change behaviours by leveraging innovation. The new normal will settle and stay with us long after the current crisis. Similarly, in fighting the plastic waste challenge, there is a real opportunity to effect lasting change.

Due to the increasing plastic waste problems, Thai government launched the plastic waste management roadmap (2018-2030) that targets to replace single-use plastic with environmental-friendly materials within 2022 and $100 \%$ recycling within 2027. The approaches will reduce plastic sent to landfills by approximately 780,000 tons a year, cut waste management budgets by Bt3,900 million annually, and reduce greenhouse gases by 1.2 million tons of $\mathrm{CO} 2$ equivalents. All parties should commit to collaborate with the government and local authorities under Thailand's 20-year National Strategy (2018-2037) that highlights growth and environmental-friendly wellbeing as well as UN Sustainable Development Goal 12: Responsible consumption and production. The Circular Economy concept is the key towards the goals with the waste management toward 3R approach.

To achieve zero plastic waste, a paradigm shift from reactive policies towards more preventive policies is needed. Philosophy of "Sufficiency Economy", which takes a middle path approach towards sustainable development on the foundations of moderation, reasonableness, prudence, knowledge, and virtue can work well with the 20-year roadmap in preventing households and communities from possessing excessive unnecessary things which finally turn 
into waste. With knowledge of plastic waste and its harm to environment, eventually to one's life, people will be aware of the problems. When realizing their actions threaten the environmental quality and sustainability, people will lower their demand of plastic items and start to follow the 3R, or $5 \mathrm{R}$ concept. When their community free of plastic waste problem with the contribution of everybody in the community, they will continue this practice and even share their experience to other communities. Besides, the intervention from government and business sector for information update, tools and equipment, as well as recycling incentives can encourage individuals, households, and communities to practice this waste management approach in long term. The philosophy underpinned by knowledge and morality can lead the way to zero plastic waste management and towards sustainability.

\section{References}

[1] Judd, A. (2020). Thai environmental experts concerned about rise in plastic usage during Covid-19 pandemic in Thailand. Retrieved 25 December 2020 from https://thepattayanews. Com/2020/08/28/thai-environmentalexperts-concerned-about-rise-in-plasticusage-during-covid-19-pandemic-inthailand/

[2] "Plastic pollution". Retrieved 27 December $2020 \quad$ from https://www.britannica.com/science/plastic -pollution.

[3] "Roadmap on Plastic Waste Management". Retrieved 22 December 2020 from https://thailand.prd.go.th/1700/ewt/thailan d/ewt_news.php?nid=7831\&filename $=$ ind ex\#: :text=The\%20Cabinet $\% 20$ on $\% 2017$ $\% 20$ April,it\%20with\%20environmentally $\% 20$ friendly\%20materials.

[4] "Thailand kicks off 2020 with plastic bag ban". Retrieved 30 December 2020 from https://www.reuters.com/article/usthailand-environment-plasticidUSKBN1Z01TR

[5] Pollution Control Department. (2019). Booklet on Thailand State of Pollution 2018. Bangkok: S.Mongkon Press.

[6] "Collaboration key to ending plastic waste". Retrieved 18 December 2020 from https://www.bangkokpost.com/thailand/ge neral/1761674/collaboration-key-toending-plastic-waste

[7] "Plastic piles up in Thailand as pandemic efforts sideline pollution fight". Retrieved 30 December 2020 from https://www.reuters.com/article/us-healthcoronavirus-thailand-plasticidUSKBN22N12W

[8] "Covid-19 pushes plastic waste rise". Retrieved 19 December 2020 from https://www.bangkokpost.com/thailand/ge neral/1906295/covid-19-pushes-plasticwaste-rise

[9] Simachaya, Wijarn, "Solid Waste Management in Thailand: Policy and Implementation". Retrieved 14 December 2020 from https://hlsesc.org/documents/8hlsesc/Thematic\%20C 1/Thematic\%20\%20C1\%20\%20Thailand\%20_\%20Solid\%20Waste\% 20Management\%20in\%20Thailand,\%20P olicy $\% 20$ and $\% 20$ Implementation $\% 20$ by $\%$ 20Dr.\%20Wijarn\%20Simachaya.pdf

[10] Pollution Control Department. "Municipal Solid Waste Management Policy in Thailand". Retrieved 9 December 2020 from

https://www.unescap.org/sites/default/files /PCD_MSWM\%20policy.pdf

[11] "Goal 12: Ensure sustainable consumption and production patterns". Retrieved 21 December $2020 \quad$ from https://www.un.org/sustainabledevelopme $\mathrm{nt} /$ sustainable-consumption-production/

[12] Schroeder, Anggraeni, and Weber. The Relevance of Circular Economy Practices to the Sustainable Development Goals. Retrieved 25 December 2020 from https://onlinelibrary.wiley.com/doi/pdf/10. 1111/jiec. 12732

[13] Ministry of the Environment of Japan. (2019). G20 Report on Actions against Marine Plastic Litter. Osaka: Ministry of the Environment.

[14] UNCRD (2018), "Thailand 3R Country Report", The Eighth Regional 3R Forum in Asia and the Pacific, 9-12 April 2018, Indore, India. Retrieved 29 December 


\section{0}

from

https://www.uncrd.or.jp/content/document s/6281Country-G-1-Thailand.pdf

[15] "The Sustainable Consumption and Production Roadmap 2017-2036". Retrieved 9 December 2020 from https://www.oneplanetnetwork.org/sites/de fault/files/thailand_sustainable_consumpti on_and_production_roadmap.pdf

[16] "Plastic-the Facts 2019". Retrieved 7 December 2020 from https://www.plasticseurope.org/application /files/9715/7129/9584/FINAL_web_versio n_Plastics_the_facts2019_14102019.pdf

[17] "The Problem with Plastic". Retrieved 5 December 2020 from https://oceanconservancy.org/trash-freeseas/plastics-in-theocean/\#: :text=Every\%20year\%2C\%208 $\% 20$ million\%20metric,currently\%20circul ate\%20our\%20marine\%20environments.

[18] "Thailand falling behind in global battle with plastic waste". Retrieved 29 December 2020 from https://asia.nikkei.com/Economy/Thailand -falling-behind-in-global-battle-withplastic-

waste\#: :text=Thailand $\% 20$ is $\% 20$ the $\% 20$ world's $\% 20$ sixth,told $\% 20$ the $\% 20$ Nikkei $\%$ 20Asian\%20Review.

[19] "Drowning in a sea of plastic". Retrieved 8 December 2020 from https://www.bangkokpost.com/thailand/sp ecial-reports/1704904/drowning-in-a-seaof-plastic

[20] Kansuntisukmongkol, K. (2017). Philosophy of sufficiency economy for community-based adaptation to climate change: Lessons learned from Thai casestudies. Kasetsart Journal of Social Sciences. 38 (2017) 56-61.

[21] Arundeea, S. and Thiphoom, S. (2015). The solid waste management according to sufficiency economy philosophy of the personal characteristics at Phra-YotMueangy Fort, Nakhon Phaom province, Thailand. Procedia Social and Behavioral Sciences 197 (): 1107 - 1112. 